\title{
EL MOVIMIENTO DE TRABAJADORES DESOCUPADOS DE BAHIA BLANCA (ARGENTINA) EN EL PERIOODO 1995-2003: UN ABORDAJE DESDE SUS SIGNIFICANTES SOCIO-POLÍTICOS
}

\author{
Pablo Ariel Becher ${ }^{1}$
}

\begin{abstract}
Resumen: A partir de la utilización de la historia oral y de la metodología cualitativa, este artículo indagará las relaciones sociales que establecieron los trabajadores desocupados y sus organizaciones en la ciudad de Bahía Blanca (Argentina) en el período 1995-2003, analizando los diversos significantes producidos en la acción colectiva, la organización social, la militancia política y las estrategias/ tácticas defensivas-ofensivas como cuerpos sociales en disputa. En este sentido el rol de los desocupados dentro de la clase obrera y el análisis de su conflictividad nos permiten reconstruir los movimientos contestatarios en la década de 1990, en el marco de la acumulación capitalista durante la etapa de convertibilidad, intentando revelar su complejidad, sus experiencias de lucha y las continuidades o rupturas con el pasado-presente.
\end{abstract}

Palabras-clave: Historia Oral. Movimiento de Trabajadores Desocupados. Militancia. Organización Política.

1 Profesor e investigador de la Universidad Nacional del Sur (UNS) y de CONICET (Argentina). Coordinador del Colectivo de Estudios e Investigaciones Sociales (CEISO) e integrante del Grupo de Trabajo CLACSO “Anticapitalismos y Sociabilidades Emergentes”. Email: pablobecher@hotmail.com 


\section{INTRODUCCIÓN}

Este artículo analiza una serie de significantes discursivos presentes en el estudio de las fuentes orales, producto de una investigación referida al movimiento de trabajadores desocupados (MTD) en la ciudad de Bahía Blanca, ubicada al sur de la provincia de Buenos Aires (Argentina), que tuvo su desarrollo más importante durante el periodo 1995-2003 (BECHER, 2017). El objetivo del trabajo implica abordar los conceptos significantes que los diversos actores encarnan en relación a su pasado-presente y que construyen a través de un relato sobre la coyuntura vivida para comprender su relación con las organizaciones políticas, su accionar colectivo y la formación identitaria. A su vez, se busca comprender la labor del propio investigador en este tipo de investigaciones y en las problemáticas especificas que se generaron en la realización de las entrevistas.

\section{EL MOVIMIENTO DE TRABAJADORES DESOCUPADOS EN PERSPECTIVA: CONTEXTO Y DESARROLLO}

El desarrollo del neoliberalismo, como parte de la acumulación capitalista en Argentina, tuvo una serie de consecuencias regresivas en términos distributivos y propició el incremento de la desigualdad social. Durante la década de 1990, en un contexto de profundas reformas económicas en toda América Latina, este proceso provocó una fuerte desregulación de los mercados, apertura comercial y privatización de los servicios públicos, lo que generó un incremento en el ingreso del capital extranjero, un patrón de acumulación caracterizado por la valorización financiera y la consolidación de un proceso de concentración y centralización económica (AZPIAZU Y BASUALDO, 2004).

La región del Sudoeste (SO) de la provincia de Buenos Aires, y en particular Bahía Blanca, no permaneció ajena a tales cambios. Históricamente, la ciudad estuvo caracterizada por su vinculación natural al puerto. Su exponencial crecimiento durante todo el siglo XX significó el desarrollo de un punto estratégico para la región de exportación de productos ganaderos y cerealeros. A fines de la década de 1970 comenzó profundizarse la instalación de industrias petroquímicas y la ampliación del complejo industrial portuario, en sintonía con una propuesta del gobierno nacional para beneficiar al capital extranjero. Las transformaciones a nivel económico y social implicaron la implementación de diversas medidas que restructuraron el empleo, con 
enormes tasas de desocupación (un 20\% en 1995), precarización laboral e incremento de las desigualdades socioeconómicas.

En el marco de la implementación de este modelo hegemónico neoliberal surgieron distintos procesos de lucha de clases y experiencias de resistencia que enfrentaron la expulsión social y pretendieron generar alternativas políticas concretas. Un conjunto importante de organizaciones sociales se opusieron a los efectos de la situación de degradación general, presentando diversas demandas con una fuerte carga de conflictividad y posibilitando definir una identidad colectiva (MANZANO, 2004). Entre las más importantes, por su capacidad de organización y por la escalada de conflictos que generó, fue la del movimiento de trabajadores desocupados y/o piqueteros (OVIEDO, 2004).

El movimiento de trabajadores desocupados (MTD) ha sido motivo de numerosas investigaciones a nivel nacional donde confluyen diversas líneas de trabajo (D'AMICO Y PINEDO, 2009). En la Argentina, se lo ha reconocido en la literatura sociológica como un sujeto colectivo que tuvo desde sus orígenes una manifiesta heterogeneidad, atravesados por diferentes tradiciones organizativas y corrientes políticos-ideológicas (SVAMPA Y PEREYRA, 2003).

En el caso específico de Bahía Blanca se desarrollaron durante ese periodo las siguientes organizaciones de desocupados: la Unión de Trabajadores Desocupados (UTD), de tendencia política independiente, que apareció en 1995, junto a otra agrupación denominada Asociación de Desocupados del Sur (con vínculos con la Partido Comunista Revolucionario): tuvieron una existencia de corta duración aunque importante, nucleando a los trabajadores despedidos del ferrocarril, de la construcción y de la administración pública; la Corriente Clasista Combativa (CCC) que tuvo una incidencia territorial importante en diversos barrios de la ciudad y que logró generar un núcleo de resistencia perdurable; el Polo Obrero (PO) ligado al Partido Obrero que apareció luego del 2000 y que tuvo una existencia ligada a la lucha por vivienda y la organización de las barriadas populares hasta el 2008; el Movimiento Territorial de Liberación (MTL) con una relación estrecha al Partido Comunista Argentino que conformó la estructura de desocupados más grande que tuvo Bahía Blanca, también con múltiples participaciones en diversos frentes sindicales, barriales y estudiantiles; la multisectorial Bahía Blanca en Lucha que agrupó a desocupados de los barrios marginales, vinculada al partido trotskista FOS y a docentes contestatarios a la dirección de Sindicato Único de Trabajadores de la Educación Buenos Aires (SUTEBA) hasta el 2002; la Asociación de Desocupados de la Industria de la Construcción Bahía Blanca 
(ADICBBA) que jugó un rol central como una fracción opositora a la conducción sindical de la Unión de Obreros de la Construcción República Argentina (UOCRA) local e intentaron brindar herramientas legales a los desocupados de la construcción teniendo como objetivo central conducir su sindicato; y las asociaciones de desocupados de la Iglesia ligadas a Caritas, con cierta autonomía a la cúpula eclesiástica más conservadora y un trabajo territorial importante ${ }^{2}$.

Estas lógicas de organización de los desocupados no se ajustaron a programas monolíticos en un solo espacio de intervención, y aparecieron fuertemente entremezcladas, ya que el eje político atravesó todas las propuestas, en contra de un mismo campo de fuerzas sociales: el Estado en sus diversos niveles y el gran capital concentrado, con sus personificaciones empresariales. Las organizaciones piqueteras fueron acompañadas por el movimiento obrero y por diversos sectores populares apoyando sus reclamos y alternando la participación con acciones colectivas de solidaridad en los barrios, sindicatos y entidades vecinales.

La mayoría de las organizaciones en Bahía Blanca estaban compuestas por obreros desocupados estatales, desocupados de la construcción y de la industria, una población sobrante fluctuante y latente, y una porción menor de sectores asociados a militantes políticos y estudiantes de la pequeña burguesía. La relación con el movimiento de trabajadores ocupados se dio en forma permanente por el trabajo de la Central de Trabajadores Argentina (CTA) y de los docentes, así como del gremio de la UOCRA, lo que le dio características interesantes al movimiento en Bahía Blanca.

\section{MARCO METODOLÓGICO DE LA INVESTIGACIÓN}

La investigación utilizó un enfoque metodológico cualitativo asociado principalmente a la elaboración y realización de entrevistas semi-estructuradas, donde se estudiaron los fenómenos sociales desde la propia perspectiva del actor, con sus significados y/o sentidos (VASILASCHIS DE GIALDINO, 2007). Por otro lado, se tuvieron en cuenta aspectos metodológicos asociados a la historia oral (BENADIBA Y PLOTISNKY, 2005).

2 Sobre la historia de la constitución de la CCC, el Polo Obrero y el MTL remitimos como marco introductorio el ya citado libro Entre la ruta y el barrio, de Maristella Svampa y Sebastián Pereyra (2003). También los autores observan de que forma la CTA y el MTA se articularon con la lucha de los desocupados en los años ' 90 . 
La entrevista, como construcción cooperativa-conflictiva de diversos sentidos y saberes, resulta una vía de acceso a la "memoria vivida" de los y las participantes (GUBER, 2001). La memoria se transforma en un registro escrito muchas veces transcripto provisoriamente, abierto y parcial, donde las expresiones tensionan lo que resulta narrado y analizado, produciendo una nueva reflexividad. De alguna manera, las entrevistas realizadas a los actores sociales nos revelan una serie de significantes sociales y culturales que exploran un ethos (una forma común de modos de vida) de acción militante y de asociación con un pasado que reconstruye la producción de una conciencia política.

La historia oral, como herramienta teórico-metodológica, está íntimamente relacionada con la constitución de memorias colectivas (SCHWARSTEIN, 2002). En otro sentido, algunos autores plantean que la historia oral es un movimiento de renovación historiográfica y de compromiso político que exige un trabajo interdisciplinario y supone nuevos desafíos en el ejercicio de la actividad investigativa, la docencia y la acción comunitaria, ya que permite el estudio de los sectores subalternos a través de fuentes no-hegemónicas (POZZI, 2012).

Más allá de las diferentes posturas en torno a la conceptualización y el ejercicio de la historia oral es importante comprender a la oralidad como un diálogo entre disciplinas que permite aportar ideas y metodologías diversas aplicadas en base a un procedimiento que recupera/reconstruye las experiencias almacenadas en la memoria de personas que vivieron ciertos procesos históricos (BENADIBA Y PLOTINSKY, 2005).

Los productos ideológicos son significaciones que parten de determinadas realidades, relacionándose dialécticamente con los posicionamientos sociales y económicos de los sujetos. Los discursos expresan relaciones de poder y de confrontación entre partes dominadas y subordinadas: dan sentido y ordenan mediante un campo de significados en donde existe una lógica confrontativa (ARTESE, 2011).

Por tal motivo, las configuraciones identitarias encuentran una íntima relación con las condiciones objetivas. Las respuestas subjetivas ante la condición de desocupación, vivida como una situación de injusticia, configuraron un código de significados que permitieron dar un conjunto de sentidos a la movilización y al conflicto social. Ese constructo no es univoco, homogéneo o estático: se generan dinámicas en relación a la percepción de los sujetos con sus experiencias del presente y del pasado. Los factores estructurales 
- la desocupación, la pobreza, la marginalidad - fueron causas importantes que promovieron la participación de los trabajadores desocupados en organizaciones políticas y sociales para resistir contra un sistema/gobierno/situación. Pero esta mirada mecanicista no debe pensarse como simple respuesta a una serie de condiciones negativas. El movimiento social tuvo múltiples causalidades, donde se entremezclan sensaciones, deseos, realidades y vivencias colectivas e individuales que permiten influir en las pertenencias políticas, las relaciones con el entorno, sus estrategias de acción y de formación de una identidad colectiva (MELUCCI, 1994).

\section{REFLEXIONES Y MARCOS DE INTERPRETACIÓN SOBRE EL “HACER DE LAS ENTREVISTAS"}

El abordaje del fenómeno del movimiento de desocupados nos sitúa en el campo de estudio de las subjetividades colectivas implicadas en la conformación de sujetos que disputan en un contexto de relaciones estructuradas por el orden neoliberal (RETAMOZO, 2006).

Enmarcamos las entrevistas realizadas dentro de un tipo particular, relacionadas con aquellas de tinte político, militante, sindical y específicamente como resultado de la memoria colectiva de los sectores populares-obreros. Las mismas contienen una serie de características propias que las diferencias de las entrevistas a otros actores sociales. Por empezar, el abordaje sobre lo político implica entablar un diálogo con individuos que atribuyen su pertenencia un espacio colectivo, donde existen expresiones concretas y acciones específicas que los identifican. De esta forma, se expresan relaciones de carácter orgánico e instrumental propios de las organizaciones, donde la conceptualización del sentido de su accionar deviene de un marco teórico a veces consciente y otras veces no. A su vez, estos relatos de vida contienen un lenguaje particular que se relaciona con expresiones típicas como lucha, militancia, organización, trabajo, entre otros, y que identifican patrones de conducta similares y propios de individuos ligados a relaciones de poder.

La estructuración de las entrevistas partió de un cuestionario básico y flexible que se llevó por escrito en cada una de las entrevistas. Su uso no fue aplicado de forma cerrada ni estática, sino que tenía por objetivo bucear sobre los aspectos personales/colectivos a través de una secuencia de preguntas en torno a tres ejes esenciales: 1) su trayectoria biográfica y política; 2) su mirada 
acerca de los procesos de desestructuración en los '90 y su recorrido como partícipe de esos procesos hasta 2003; 3) la especificidad de las organizaciones de desocupados, propia y otras, solicitando una caracterización y reflexión final, a modo de balance.

A su vez, se tomaron en cuenta las siguientes variables básicas: 1) Edad y sexo (condicionantes importantes de las formas en que actúa la memoria, pero también del marco interpretativo que tienen los entrevistados/as sobre el entrevistador); 2) Ocupación laboral en el momento de estudio y actual; 3) Organización perteneciente o participante indirectamente y vinculo jerárquico en la misma ${ }^{3}$.

Los/as informantes seleccionados/as para esta investigación fueron proporcionados en muchos casos por los propios entrevistados o por la lectura de fuentes documentales. Se realizaron un total de 22 entrevistas (algunas grupales) a 26 personas que tuvieron su participación como actores concretos en las distintas organizaciones de desocupados o fueron referentes sindicales y/o políticos que acompañaron al movimiento. De las 22 entrevistas, una se realizó a través del correo electrónico y en seis de ellas participaron dos personas simultáneamente.

En las narrativas de los/as entrevistados/as surgieron elementos del pasado histórico en relación a un conjunto de tradiciones históricas políticas, de verdades afirmadas y de sentidos de pertenencia que influyeron fuertemente en sus memorias. Esta situación genera un discurso mediado por la expresión de lo que pasó, que tiende a ser reconstruido por el sentido de la organización. Hay una memoria hegemónica que se impone susceptiblemente, aunque muchas veces en las reflexiones y silencios esas formas de decir y hacer las cosas resulten cuestionadas por los/as entrevistados/as. En este sentido, hay una reconstrucción discursiva que se expresa por contener una visión principal de la realidad: las cosas fueron así y de esa forma serán:

Hay dos tiempos en la historia de los desocupados que son los '90 y el 2001 (...) son dos momentos de la clase (...). En los 90 todavía los desocupados tenían una estructura sindical que convierten a ese movimiento en la búsqueda de trabajo

3 Véase ANEXO al final del artículo donde se detallan algunas de las características principales de los/as entrevistados/as.

4 El tamaño de la muestra fue limitado por el punto de saturación sobre la temática propuesta, cuando comienzan a repetirse las descripciones de las mismas acciones y observaciones. Para ello resultó propicia la utilización de la técnica de "bola de nieve" (snowball) que permitió el contacto con informantes clave que dieron la llave para conocer a las personas que fueron entrevistadas, y que a su vez ofrecieron otros contactos. 
(...). Y en el 2001 la actuación de los desesperados, ya muchos de ellos no tenían nada que ver con la práctica sindical de los '90. Unos son hijos de "ramal que para, ramal que cierra" (...) muchos compañeros ferroviarios (...) y los otros son hijos de la desesperación de la debacle, de un Estado que virtualmente desaparece $(\ldots){ }^{5}$

Partimos de procesos históricos que ocurrieron hace más de veinte años. Pese a la distancia temporal, las variables relacionadas con la exactitud y fidelidad del recuerdo no fueron un problema en el análisis, debido principalmente a la notable capacidad de "conservación de la información" que pudo verificarse de los/as informantes.

Sin embargo, esa exactitud memorialista contrasta con una reconstrucción simbólica que constituyó una cimentación del sentido del pasado en un acto de re-memorización ajustada al momento y las ideas predominantes desde el presente. Esta situación provocó que la narración de los/as entrevistados/as ocultaran o silenciaran algunos condicionantes esenciales para pensar las prácticas políticas de las organizaciones en sí mismas y sobre otras, o se autoreferenciara en términos de participación netamente positiva. Los miembros de organizaciones políticas, principalmente los líderes y referentes políticos-partidarios, en muchos casos expresaron su mirada histórica del pasado reconstruida por los hechos que interpretaron desde el sentido orgánico, desde un "nosotros les dijimos, nosotros fuimos los hacedores de... realizamos una experiencia territorial para llevar conciencia... nuestra historia es la lucha de un partido que intenta organizar, estructurar a los trabajadores...”.

Otra característica de las entrevistas realizadas fue la disociación intencional del entrevistado/a con el tema específico de discusión. Esta técnica de "encubrimiento" de lo que debe decirse o no, forma parte del entrenamiento mismo de los militantes más formados a la hora de expresar sus acciones. No ir "directamente al grano" de los hechos, sino bucear en los aspectos relativos al contexto, manifestar una explicación general del contexto socioeconómico e invisibilizar las prácticas cotidianas, expresan estrategias de conversación que tienen por fin esperar las respuestas del otro en términos de posicionamiento político.

Al establecer un puente entre dos mundos de significación, entre el llamado nativo (muy cercano a nosotros en lo cotidiano) y el investigador, la experiencia de campo se enriqueció notablemente, con la participación en

5 Emiliano, referente de la CTA y del MTL. Entrevista realizada el 9 de marzo del 2015 en Bahía Blanca. Entrevistador: Pablo Becher (PB). 
encuentros de carácter reflexivo, donde se generaron momentos, anécdotas y espacios de interrelación. Sin embargo, esta experiencia estuvo atravesada por momentos de tensión y desconfianzas, que no pueden explicarse meramente por el estado de ánimo de los entrevistados/as o su personalidad, sino que tiene que ver con las formas en que se expresa la militancia política. Las organizaciones generan mecanismos de seguridad sobre la información que manejan, no solo para resguardar la propia estructura sino también para protegerse a sí mismos y a terceros. Las sospechas sobre las intervenciones periodísticas o académicas impactan en aclaraciones acerca de quiénes somos y que buscamos (los que investigan), cuales son los motivos reales del acercamiento y que se hace con la información recabada.

Retomando alguno de los análisis de la antropóloga Paula Fernández Hellmund (2013) podemos observar una serie de problemáticas comunes en el trabajo con militantes. Una de ellas es la "objetividad" y la distancia que pretende el/la investigador/a, que se dificulta por el hecho de compartir espacios con los/as entrevistados/as (al habitar en la misma ciudad, pueden converger en espacios y experiencias colectivas: una marcha callejera, una protesta, la pintada de un mural, etc.); otra de las problemáticas se relaciona con la formación académica que tienen algunos/as entrevistados/as, que conocen la disciplina y manifiestan un particular interés sobre qué se va a hacer con el trabajo, con quiénes se compartir, cómo se investiga, etc., y por este motivo, introducen sus puntos de vista aconsejando sobre la mejor forma llevarlo a cabo. De este modo, los/as militantes recuerdan que son "autoridades" en el tema y que uno debe asumir una relación de subordinación indirecta sobre lo dicho. Los/as entrevistados/as observan y estudian al entrevistador, lo cual se relaciona con la forma en que los discursos científicos reingresan en los contextos sociales que analiza.

Otro tema relevante a la hora de realizar entrevistas se encuentra atravesado por las relaciones de género y edad del entrevistador/a que generan e influyen significativamente en la información que predispone el/la informante ${ }^{6}$.

En este sentido, la investigación realizada posibilitó la reflexión acerca del rol del propio entrevistador en la entrevista. Si el objetivo implicaba reconstruir la información sobre determinados sucesos, a través de preguntas que sirvieran como impulsoras para reflexiones ampliadas, ¿qué puede suceder cuando

6 ¿Qué información se ha podido obtener teniendo en cuenta que el entrevistador es de género masculino y joven? ¿Hubiera obtenido lo mismo si las preguntas la realizara una mujer? ¿O si se tomara por una persona de más edad? 
nuestra visión de la militancia, las relaciones sociales y las formas de hacer política son cuestionadas e interpeladas por los propios entrevistados/as? $\mathrm{Si}$ bien pueden ser formas sutiles en que el informante pretende introducir su visión en nuestras investigaciones, ¿hasta qué punto no expresan la búsqueda de una trasmisión o la confirmación de una perspectiva de lo que las organizaciones pretenden que se recuerde?

Hay un estrecha vinculación en la historia oral entre la forma de producción de la propia fuente y lo que estas pueden revelar (SCHWARZSTEIN, 2002). Esta cuestión fue reinterpretada cuando se solicitó a algunos dirigentes y referentes de las organizaciones que permitieran "hacer un contacto" con otros actores sociales más ligados a la base y la respuesta fue evasiva, desinteresada o sepultada en el olvido: ¿que tendrán para decir algunas bases sobre las dirigencias?

Las expresiones de los/as entrevistados/as fueron particularmente significativas como parte de una lectura mediatizada por el/la informante. Las miradas, gestos y muletillas fueron parte del lenguaje corporal que expresaron los entrevistados/as muy ligados a sentimientos de rabia, frustración e impotencia pero también a optimismos, esperanzas y sentimientos de aprendizaje.

¿Qué sucedía con las condiciones de vida cotidiana de los sujetos? Esta cuestión interesante aparece muchas veces entre las anécdotas de los entrevistados/as, en circunstancias que consideran poco relevantes a la hora de expresar su relación con el pasado. Sin embargo, la profundización de estos relatos de los actos rutinarios nos demuestra las acciones sociales y las prácticas que los sujetos realizaban, más allá de lo discursivo.

\section{SOBRE LOS SIGNIFICANTES DISCURSIVOS EN LAS ENTREVISTAS A LOS ACTORES SOCIALES}

La búsqueda de una asociación libre y una categorización diferida (GUBER, 2001) se ejerció mediante la formulación de preguntas abiertas que se fueron encadenando sobre el discurso del entrevistado/a hasta configurar un sustrato en el cual se pudo reconstruirse el marco interpretativo de los actores y su lógicas. En estado de atención expectante, se produjeron ciertas afirmaciones que redundaron en la aparición de varios conceptos o significantes centrales de análisis. Entre ellos podemos mencionar: necesidad, conciencia, militancia, lucha y trabajo. 
Cuando fue posible evaluar una clara tensión entre lo que se recibe como prebenda/beneficio ante la necesidad, y lo que se obtiene mediante la lucha, la subjetividad se condensó en la palabra necesidad, entendida como la búsqueda de satisfacción de derechos básicos y de alimento, que presiona sobre el individuo a la aceptación pero también a la organización para su reivindicación.

Los planes sociales se acoplaron a los sentidos de lucha y necesidad desde un punto de vista que superaron las visiones economicistas, propias de las lecturas que entienden el reclamo como una reivindicación donde la cooptación jugó un rol importante. La trama fue mucho más compleja, porque los planes permitieron también la posibilidad de gestar un poder creador para idear, hacer y reflexionar desde los sectores populares. Jerónimo Pinedo sintetiza algunas de las apreciaciones subjetivas que adquieren los planes sociales, que surgen desde las organizaciones: 1) como algo que se obtiene de otro que da; 2) como una herramienta para organizar y construir una agrupación político-territorial; 3) como algo que se conquista con la lucha, 4) y como algo que se obtiene a cambio de una contraprestación laboral (PINEDO, 2009). Estas visiones conforman un complejo entramado de significados, en el seno de una figuración social (retomando a Norbert Elías) en la cual quienes participan de la organización se hallan involucrados.

Lo que nos moviliza a nosotros y nos lleva a corrernos de la periferia hacia la exigencia a la municipalidad y el centro y al encuentro piquetero, la asamblea de desocupados y el congreso de la vivienda fue la necesidad (...) ahora la conciencia nos llega desde afuera a entender cómo funciona el sistema y quién era el enemigo...(...) ahí nos avivamos de lo que significa la política; los punteros políticos llevaban los pañales de acá, los otros estaban inaugurando una huerta y sacándose fotos, y nosotros estábamos cagado de hambre en el barro, sin garrafas, defendiéndonos a los palos cuando nos venían a cortar la luz...(bronca) (...) ya había llegado la pobreza y había calado profundo... y nosotros tuvimos a Matías el nene acá que le agarró una gastronteritis... y se desnutre; imagináte con esa gastronteritis... mal alimentado... lo llevé a la salita y ahí la enfermera y la médica me dicen: mamá ¿vos no te das cuenta que tu hijo esta desnutrido? ¿No te das cuenta?... (tristeza) Eso fue un golpe terrible, porque nosotros no nos podíamos dar cuenta de nuestra propia situación, sino reaccionábamos, por eso nos saca la necesidad... por eso a veces me dicen 'vos sos una zurda silvestre, te saca la necesidad' (Risas) (...). ${ }^{7}$

7 Sandra, miembro del Rincón de los Chicos (organización barrial) y de Bahía Blanca en Lucha. Entrevista realizada junto a Raúl, su compañero, el 11 de mayo de 2015 en Bahía Blanca. Entrevistador: PB. 
(...) había mucha gente (...) iban chicas jóvenes que iban con hijos y eso... qué sé yo éramos como treinta y cuarenta, se juntaban... y entonces vos que trabajaste, nunca te aportaron nada, ganaron los más ricos y ahora nosotros tocando una olla en el centro para que te den un poco de mercadería ...y después volver otra vez esperar un año para que te den nada... en ese entonces te miraban de pies a cabeza para darte 200 pesos por mes...todo una lucha, todo así...entonces cada vez que vos ibas a, lo que yo sentía y yo creo que todos los sentíamos, cada que decían una marcha y era con bronca.... ¿por qué tenemos que hacer esto? Había personas que eran más viejas que yo (...) tocando por un bolsón... (Tristeza y frustración en la mirada) y acá se tenía que madrugar... hacer pan y darle un pan a cada uno a la mañana temprano...y yo puse el merendero porque yo veía que los chicos necesitaban... si hasta 70 chicos tuve $(\ldots){ }^{8}$

En el ámbito de Bahía Blanca, la continuidad del gobierno radical y su red de contención social, junto a organizaciones afines, le permitió consolidar un rol activo en la ejecución y administración de los planes sociales (siempre en conflicto con la Provincia), dejando poco espacio para la administración por parte de las organizaciones de desocupados, que debieron demandar constantemente y empujar sus reivindicaciones para ser correspondidos. Hubo debates profundos en torno a esta cuestión que generaron disputas internas.

La noción de trabajo genuino y el reparto de horas de trabajo, demandado al gobierno, siempre estuvo presente en todas las organizaciones de desocupados como un planteo excluyente y superador, contraponiéndose al trabajo subsidiado, aunque por determinados factores se terminara posteriormente aceptando como instrumento táctico. Esta contradicción tiene su explicación en las alternativas reales que podían generar las organizaciones de desocupados, frente a una situación económica y social que achicaba el margen de maniobra y un sector político que hábilmente disminuía las oportunidades de acción, en un contexto de desprestigio y debilitamiento de los lazos punteriles, con la finalidad de generar nuevas formas de dependencia.

Esta dependencia con el Estado es parte constitutiva de un vínculo que resignificó las formas de lucha o acción colectiva confrontativa y la identidad misma de las organizaciones, que se expresaron y construyeron en torno a un espacio y un alineamiento social entre fuerzas contra las clases dominantes en el poder. El plan criticado y enjuiciado como "pernicioso" también sirvió para consolidar los reclamos y generar "un puesto de lucha" que trascendiera la

8 Rosario, referente de base de la CCC. Entrevista realizada el 6 de abril del 2016 en Bahía Blanca. Entrevistador: PB. 
mediación con el gobierno de turno y se convirtiera en un derecho adquirido.

Otra noción que surge fue la de conciencia. La conflictiva relación entre asistencialismo y la construcción de una conciencia de clase, entendida como una forma de asumir una subjetividad ligada a un posicionamiento socio económico. En este sentido nos referimos a la conciencia como un proceso de formación y construcción ideológico-político que se sustenta con la clase social de pertenencia o de solidaridad con los intereses de otra clase con la que se relaciona. El asistencialismo se veía como una forma de manipulación, una trampa que no permitía desarrollar la conciencia política para que los sujetos se vuelquen por sus demandas.

Iba gente de obra, en su gran mayoría gente mayor, gente que había estado toda su vida de obra, muy acostumbrada a laburar, yo no podía creer que estuvieran ahí...o gente de frigorífico, gente que un día para el otro se les despertaba... tenías que verlo en algunos momentos como cuando hicimos el corte, llorando de impotencia...eso te iba formando te iba curtiendo un poco la cabeza...no era una joda estar acá...fue muy fuerte, escuchar historias de personas que laburaron toda su vida y que terminen así (...) para nosotros era difícil aceptar los planes... yo por ejemplo de esa época hasta ahora jamás acepte los planes...te los ofrecían como si fuera tomá y callate... lo que te daba el tema de aceptar, igual se aceptaban el tema de los alimentos... (...) a mi cuando me la dieron se la tire en el hall de municipio frente a los medios y les preguntaba a ellos que no estaban presentes ¿cómo podían alimentar a la familia con un paquete de yerba una bolsa de fideos, dos de arroz y una de azúcar, y un aceite...? Se las deje tiradas en el hall... había muchas necesidades dentro de nuestro grupo y teníamos muchas discusiones, por qué los demás grupos aceptaban garrafas, alimentos y un montón de cosas y teníamos discusiones entre los compañeros y algunos se iban, porque la desesperación era mucha, no la podían soportar... y bueno quedamos siempre atrás de los demás $(\ldots){ }^{9}$

La militancia aparece como otro significante importante, generado por la pertenencia a una organización política concreta, un accionar dentro de la misma y como una práctica de vida. En este sentido, la militancia tiene diferentes sentidos dentro las organizaciones de desocupados, dependiendo de qué posición ocupen los actores sociales dentro la misma, ya sean líderes, referentes o militantes de base. En la reconstrucción y análisis de las experiencias organizativas, se parte en general sobre el punto de vista de los líderes, que intentan resumir lo que el movimiento o la agrupación "piensa o

9 Entrevista a Andrés, referente de base de Bahía Blanca en Lucha. Realizada el 13 de abril de 2015 en Bahía Blanca. Entrevistador: PB. 
hace" (QUIRÓS, 2006). Pero detrás de estas apreciaciones se esconden diferencias importantes en torno a la concepción de la militancia, el sentido de la propia vida y la forma en que deben llevarse a cabo las prácticas políticas.

En la sociología clásica se entendía que entre los/as integrantes de una agrupación, corriente o movimiento, se producía una socialización, como un mecanismo de integración social, donde se interiorizan determinadas reglas que permiten la constitución de un "yo" y de la propia subjetividad (VÁZQUEZ, 2010). Otros autores parten de la idea de reemplazar el concepto de rol por la de experiencia social (DUBET, 1994 [2011]), donde se presenta un intermedio entre la interpretación acabada y la totalmente libre de la adquisición de conocimiento y donde los individuos o los grupos se ven confrontados a lógicas de acción autónomas y tienen la capacidad de poder interpretarla.

\begin{abstract}
¿Tenía nombre el Merendero? En ese sentido yo también tenía bronca, porque era el merendero de Villa Nocito, no tenía nombre ninguno de los merenderos tenia nombre, habían como treinta merenderos, pero no dejaban que le pongan nombre... ahí era donde yo tenía un poquito de bronca, porque vos no podías hacer lo que vos sentías y lo que vos creías que ibas a hacer bien... una vez casi me echan rajando [por repartir el guiso sin el consentimiento de la coordinadora de la organización] (...... ${ }^{10}$
\end{abstract}

(...) el movimiento de desocupados era muy heterogéneo, muy desorganizado con gente que no entiende de disciplina, mayoritariamente con muchas dificultades para plantear objetivos políticos y llevarlos consecuentemente, entonces habia un pequeño que entendía y un gran sector que no entendió... (...) en este sector que entendía en el primero quedaron algunas remanencias, de gente que despues nos acompañaron en la organización del Polo Obrero y del partido...Y la mayoría siguió los devenires de la economía argentina, siguió participando en los distintos movimientos, organizándose en cooperativas, que tuvieron un tiempo de funcionamiento y despues dejaron a la gente a merced de las circunstancias. ${ }^{11}$

En la socialización política que se produce en el movimiento de desocupados, proceso inacabado y en permanente cambio, se deben contemplar las distintas etapas y esferas en las que se produce la experiencia social. En este sentido, las nociones políticas, los conceptos y las identidades aparecen entremezcladas con las ideas preconcebidas de las personas y con los procesos de aprendizaje que van adquiriendo, donde el conflicto social y las acciones

10 Entrevista a Rosario. Idem anterior.

11 Entrevista a Mario, referente del Polo Obrero. Entrevista realizada el 13 de marzo de 2015, por PB. 
colectivas juegan un rol fundamental en la adquisición de una serie de prácticas e ideas militantes.

La UTD era muy pluralista, no se fijaba mucho en el tema de quien debía estar o si respondía a una línea política...estaban en contra de todo, nos unía el tema del desempleo... después si algunos se fueron formando, escuchando a los militantes de izquierda...(...) había términos que no conocías, imperialismo, capitalismo, términos, formas de organizarse, el tema de las asambleas permanentes, yo desconocía todo ese movimiento [aunque conocía a nivel sindical](...) había términos o tipos de izquierda... yo llegaba a mi casa y tenía carpetas llenas con volantes, periódicos del partido, entonces me despertaba el interés por ahí y llamaba a alguno y le preguntaba che explicáme qué es esto, ¿por qué se están peleando contra el otro grupo, si piensan igual que ustedes, la mayoría dicen lo mismo en el diario? (...) y cuando fui a Buenos Aires fue peor porque allá había diez mil partidos de izquierda... y todos te venían con sus formas de decir las cosas, pero al final terminaban en lo mismo, entonces uno no terminaba de entender, por qué no se logra una unidad...y te termina cansando...la mayoría de los partidos te enseñan que tenés que hacer pero no lo aplican (...) (sentimiento de resignación en la voz). ${ }^{12}$

Las narrativas de los militantes invitan a reflexionar sobre las diferencias entre los referentes jóvenes, los lideres con experiencia sindical o territorial que son la cabeza de las agrupaciones y los militantes de base (VAZQUEZ, 2010). En el discurso de los líderes aparece expresada esa idea de incorporar la conciencia política y efectuar una vida militante comprometida con los ideales "socialistas $y$ revolucionarios". En cambio las bases tienen discursos más reticentes y complejos, donde aparece motivaciones de participación política, experiencias de vida asociadas al maltrato, a las injusticias vividas diariamente y a la búsqueda de un beneficio material para su familia, como una mera "acción instrumentalista", pero que en el fondo encierran procesos de politización que componen su compromiso con la organización y el reconocimiento que tienen de la misma.

Si bien estas ideas discuten el romanticismo con que se ha visto a los sectores populares, se cuestionan también la simplicidad con la que se relaciona al desocupado como "un sujeto que se moviliza por un plan". En este sentido, se observa cómo "el plan se gana movilizándose", "se arranca al Estado" o "se sostiene por la lucha", frases que sintetizan criterios de participación e ideales formados por la relación con el espacio colectivo. En la disrupción en el ámbito público y en los medios aparece también la idea de reconocimiento, de obtener 
una voz que fue silenciada.

Por otra parte, aparecen continuidades entre las motivaciones de ambas parcialidades internas, ya que los dirigentes entienden la necesidad de "hacer una carrera política”, cuestión que los militantes de base comprenden, pero critican. Los jóvenes observaron la relación entre discursos y hacer político, que muchas veces no mostraba una correspondencia, lo que motivó profundas rupturas en las organizaciones.

En estos espacios se entrecruzan redes de socialización, atravesadas por diferentes vínculos (afectivos, familiares, vecinales, militantes), que desbordan la propia participación en las organizaciones y entretejen relaciones de fraternidad, respeto, pero también de rivalidad, competencia y antagonismo entre ideas y actos.

En las organizaciones de desocupados es posible reconocer mecanismos de distinciones, que constituyeron una fuente de significación en las relaciones de poder, no solamente en las relaciones entre géneros, sino también intergeneracionalmente. Los mecanismos de puntaje implementados por la CCC para la asignación de bolsones de comida ${ }^{13}$, las críticas de los militantes a los que viene "de la joda" con conductas liberales, y los hechos de conflictividad diversos en los que participaron los desocupados, nos revelan que la militancia tenía un fuerte basamento en la necesidad del compromiso ético con un hacerdecir, pero que implicaba una permanente evaluación sobre la participación o no en acciones colectivas o asambleas. Esta valoración medía sistemáticamente a los participantes y los diferenciaba públicamente en las intervenciones públicas. Las mujeres mostraron un creciente nivel de compromiso, que muchas veces no se correspondía con un mayor acceso a las cúpulas de decisión.

Las trayectorias de los desocupados fueron variables y heterogéneas, pero los MTD intentaron en todo momento homogeneizar una identidad definida a través de una construcción política delineada por el partido pero también por la experiencia. La línea estratégica que se afianzaba desde lo territorial, tuvo su expresión en algunas organizaciones como la UTD, la CCC, el MTL, en parte en el Polo Obrero y en Caritas, como organizaciones que influyeron

13 En algunas entrevistas realizadas a líderes de la CCC se expresaba que los mecanismos de puntaje se habían implementados para asegurar un reparto igualitario y no conflictivo de los planes sociales y los bolsones de comida. Se asignaban puntajes por la participación en acciones organizativas, manifestaciones, paros, participación en marchas y convocatorias de la organización, entre otras expresiones. Esta metodología - decían los referentes - "permitía incentivar a la conciencia de clase y a la solidaridad con el otro, y no al entregar sin hacer nada..." (Entrevista a Francisco, referente y líder de la CCC en Bahía Blanca, 15 de abril de 2015, realizada por PB). 
profundamente en la idea de organización de las barriadas populares. Algunas de ellas tenían una perspectiva de la militancia que debía integrar las reivindicaciones básicas vecinales con una organización política de masas. No hubo una línea interna que tuviera como norte estratégico el autonomismo o la construcción de un poder popular, como en el Conurbano bonaerense o en Salta. Estas organizaciones privilegiaban la acción concreta, donde se rehabilitaba el componente básico y esencial, tanto en las condiciones de vivienda, como en la urgencia alimenticia y los servicios públicos (agua, electricidad y gas).

Por último, entre los significantes más importantes podemos identificar la acción colectiva en el conjunto del MTD como una expresión de lucha de los sujetos que participan. Las experiencias forman parte de la construcción intersubjetiva de una fuerza social que va cobrando noción sobre el significado de participar políticamente en la propia acción. En este sentido, la lucha se vuelve una experiencia de apropiación y de conocimiento sobre el mundo y sobre las formas de disputar y enfrentar a los otros (Estado, clases dominantes, entre otras concepciones políticas). La lucha fue moldeando una identidad que se instituyó como fundante de una serie de prácticas que determinaron el ser y el hacer de las organizaciones.

Fue en Septiembre [1995], para el día de mi cumpleaños armamos la carpa. De la Municipalidad nos tomaban el pelo, a nosotros y a todos los desocupados, porque a los que estaban en la cola para anotarse les decían -"no hay trabajo, vayan a anotarse ahí que están dando trabajo" y la gente venía a anotarse. Nosotros no estábamos dando trabajo. Les decíamos (...) te anotamos, dame los datos, pero tal día te espero acá en la plaza porque si no reclamamos todo juntos no va a funcionar". Llegó el día, yo tenía un "renaulito", un Renault 6 un viejito, que todos los días íbamos con la mesa arriba del techo y dos sillas. Llegamos de ese viaje, impresionante la gente que nos estaba esperando ¡Impresionante! Ahí nomás, enchufamos el equipo de audio y Empiezo a hablar que había que ir al Concejo Deliberante, encarar a los Concejales, y traerlos a la Municipalidad a ver si entre todos se arreglaba. Y salimos para el Concejo Deliberante por la calle, agarramos mano porque ya teníamos mucha experiencia de no agarrar en contra mano, dimos toda la vuelta. En el Concejo Deliberante ya había un cordón policial. Y yo venía adelante, con $\mathrm{H}$. y dos o tres más encabezábamos la marcha, y digo "bue acá sonamos", igual encaramos, y los milicos se abren, y paso. Y miro para atrás, ¡qué! ¡Cómo para no abrirse! llegaban cuadras de gente que venían atrás nuestro... (orgullo y felicidad en el habla). ${ }^{14}$

14 Gerardo, integrante de la UTD. Entrevista realizada junto a Ana, su compañera, el 11 de febrero de 2015 en Bahía Blanca. Entrevistador: PB. 
Si bien no todas las luchas sociales constituyen una lucha por el poder, entendido como una lucha por la hegemonía, es posible observar que para los sectores de trabajadores desocupados - y populares en general - el problema del poder político no se encuentra separado del problema de la urgencia por la sobreviviencia. La resolución de los problemas vitales resulta un problema político en sí mismo, donde aparece un entramado complejo entre movilización, violencia y conflictividad como formas de resolución de una marginalidad, una exclusión ejercida sistemáticamente "desde arriba". Esta situación se aplica también frente al otro, primero como autodestrucción y luego a través de la rabia y el odio desbordante contra todo lo social (FANÓN, [1961], 2007). La rabia y el odio de clase, como la misma violencia, son formas de conciencia política y no de irracionalidad.

En este sentido, la lucha aparece como una forma de concientización de una situación dada, donde la política aparece re-significada dentro de una ruptura del tejido social, de una situación vivida como injusta. Si para algunos puede ser visto como una oportunidad política de politización de los sectores populares, más bien podríamos argumentar que se trata de un momento de tensión y enfrentamiento que tiene por objetivo generar mecanismos de cohesión y legitimidad de demandas puntuales.

Los MTD surgieron en un contexto de resistencia y propusieron en general un programa estratégico de carácter defensivo donde la conflictividad jugó un rol esencial en la formación de una conciencia política. Fueron espacios de construcción colectiva atravesadas por el conflicto y el poder. Esto no significa que no se hayan propuesto tácticas ofensivas en términos de reivindicaciones y acciones de conflictividad sobre derechos adquiridos, que debían ser correspondidos por el Estado o por las propias empresas privadas.

La conformación del movimiento de desocupados en Bahía Blanca tuvo como eje la construcción de una gama de acciones ligadas a un repertorio de lucha de calles - el piquete, el corte de calle, las asambleas, la olla popular y las manifestaciones - y por otro lado, al despliegue de acciones y experiencias con matrices comunitarias, sindicales y territoriales (típicas de organizaciones peronistas, sociedades de fomento y comunidades de base eclesiásticas). La sedimentación de ese espacio de lucha y de "devolución de la palabra silenciada" implicó la reconstrucción de los lazos sociales vecinales y políticos, que se volvieron importantes para los propios actores en juego. Pero también significó un espacio para explorar la unidad en la lucha entre diferentes expresiones políticas y sociales, como un factor de alianzas entre fuerzas sociales y políticas 
efímeras, con reivindicaciones heterogéneas pero expresadas en conjunto.

Las formas de intervención del Estado, en sus diversos niveles, fomentaron la protección de los intereses del capital y la represión a los sectores subalternos como una muestra constante de manipulación y poder coactivo. Su metodología se sintetizó en un muestrario aprendido de manual: reprimir, ignorar y (a veces) negociar, con incumplimiento de las cláusulas consensuadas.

Por lo tanto, los procesos de movilización social, más allá de ser pensados como respuestas a las políticas neoliberales, forzaron verdaderos cambios al interior de la estructura estatal, potenciando sus capacidades de construcción, y manifestándose masivamente en contra del modelo económico y político.

En tanto entrevistas en torno a lo político y la política, las percepciones que se generan entre el entrevistador y los /as entrevistados/as se mantuvieron en una zona de contradicciones y luchas de significantes donde se combinan aspectos éticos, políticos y morales entremezclados con percepciones y experiencias actuales y pasadas (POZZI, 2012).

¿Qué significantes políticos y silencios aparecieron? Por un lado un concepto significativo fue el del socialismo. No tanto por lo que significa en términos marxistas, sino por la forma en que fue reinterpretado y asimilado. Los militantes de base se expresaron en términos más reivindicativos en torno a sus prácticas, valorando el conocimiento de las "problemáticas reales" de la gente, y en general, sin una formación política en la izquierda revolucionaria, pero compartiendo en el fondo el sentido de la lucha y del movimiento.

PB (entrevistador): ¿Qué es el socialismo para ustedes?

Rosario: No (pausa).. no entiendo yo... hay muchas cosas que no entendí...

PB: ¿eras vos o era todo el grupo?

Rosario: Si, a veces más de la mitad...no entendía ni lo entiendo ni nunca lo entenderé...porque tenés mil maneras de pensar, bien, mal o porque... no es que yo te diga es así y no es... porque yo no llegue a ningún lado... yo quería hacer la Chivitela (risas)... La Chivitela [era un personaje que] no hacía nada yo quería andar con una carpeta acá y no hacer nada... Viaje mucho conocí mucha gente... (...) pero bueno yo ya no podía seguir $(\ldots) .{ }^{15}$

PB (entrevistador): ¿Qué es para ustedes la revolución?

Ana: La revolución para mí, te voy a hablar del caso mío, lo que yo aprendí en el partido, la revolución es el cambio total de las cosas, no remendar ¿viste? Sino que cambiar todo, cambiar el sistema. 
Gerardo: En vez de éste gobierno de chorros que nos están gobernando que gobiernen los trabajadores pero con otro sistema, sino el trabajador que vos pongas ahí arriba se vuelve chorro también. Porque puede ser el tipo más honesto, pero la plata corrompe a las personas. Entonces revolución es eso, cambiar el sistema, el sistema de gobierno... por los votos no se hace nada...pero con la revolución es distinto porque agarrás un palo... se tiene que dar violentamente...Cuando el pueblo entero se manifiesta a favor de la revolución, siempre va a haber un grupito que va a estar en contra, el grupito que está privilegiado va a estar en contra, y esos se van a defender con uñas y dientes, y van a apoyar la contrarrevolución...

Gerardo: Mi concepción de la revolución es parecida a lo que dijo Ana, pero va más allá, es internacionalista. Los trabajadores del mundo se tienen que unir, como lo estuvieron en alguna época. Tenía un problema la fábrica Ford de acá y paraba la fábrica Ford de Inglaterra, de todos lados. Tenemos el problema de las fronteras. ${ }^{16}$

La comprensión del socialismo desde un punto de vista que valora la acción y el "buen gobierno" resulta una síntesis diaria de los sentidos asignados por los referentes de base.

La idea del socialismo figura como una de las formas de incomprensión que las propias dirigencias políticas han tratado de develar dentro de sus propias explicaciones: saben que la revolución no es solo un anhelo sino una lucha de toda una vida y que su penetración y discusión genera un acercamiento a una decisión lo más colectiva posible.

¿Qué significó la izquierda como discurso y de acción política para las masas de desocupados? ¿Hubo autocríticas a las formas en que se actuó desde un punto de vista ideológico? La fractura y la derrota del campo revolucionario trajeron aparejados un conjunto de replanteos, que se generaron a sí mismos y contra todo lo que alguna vez tuvo sentido para el militante. Al ser derrotada la fuerza moral, que empuja los sentidos más profundos en torno al porque se milita y con qué objetivos, las dudas aumentaron, estimulando la caída de una representatividad idílica que se tuvo sobre las formas asumidas como verdaderas. Si bien en toda la investigación hemos escuchado algunas autocríticas, en general prevaleció el carácter representativo de la organización con una mirada valorativa de todo lo realizado. Una de las entrevistas más reveladoras al respecto fue la realizada a un desocupado de base, que luego se convirtió en referente de su agrupación, y expresa algunas apreciaciones: 
La izquierda tiene un discurso que para el que es joven el tema de escuchar revolución, rebeldía y todo eso es que te alimenta...ellos ven a los jóvenes como la vanguardia de la lucha... pero hay un manejo como muy...como te puedo decir, (...) los manejan como rebaño, a los jóvenes es muy fácil meterles ideas en la cabeza, porque están en un estado de rebeldía natural...y eso es lo que a mí me pasó, yo me creí mucho de las cosas que ellos me decían, a pesar de que a mí no me gusta leer, tengo mucho libros que me han regalado ellos, periódicos y cosas que hablaban de la revolución rusa, de los procesos latinoamericanos, y yo me ilusionaba mucho con ellos... pero veía que ellos iban a contraviento y cada vez veía que se me despertaba más el interés, y cada vez leía más...y hasta que llegó el 2003 las elecciones y lo que predicaban no era lo que iban a hacer, se presentaron a elecciones...y yo desde ese momento no he votado, no he participado de las elecciones, creo que soy y fui un anarquista (...) yo veía que ellos remontaban el barrilete alto como para atraer a los jóvenes con el tema de la revolución pero cuando vos llegabas a pedir armas, ya sean armas políticas o....armas, no sabían que decirte, era como el discurso no era lo que hacían (...)

(...) los obreros históricos que llevan más de veinte o treinta años en obra, vos te sentás a charlar en una obra y son mucho más revolucionarios ellos que cualquiera...o sea lo que tienen los partidos de izquierda que si he observado es que la mayoría son personas que hablan de los trabajadores pero no son trabajadores, provienen de la clase media y de ahí para arriba...hay burguesía dentro de la izquierda aunque no la quieran reconocer es otra cosa (...) las cabezas están representadas por personas que no conocen el hambre, el frío la realidad de un barrio, no conocen el tema de sufrir las necesidades básicas (...) un obrero sin preparación sin estudio sin nada, puede llegar a dar cátedra en la universidad, no hablo de mi sino de gente más grande que ha estado toda su vida trabajando (...). ${ }^{17}$

En este relato se condensan algunos de los debates típicos de los militantes de izquierda sobre la contradicción entre el hacer y el decir, la relación que se establece con lo generacional y con los registros ideológicos que componen el acervo militante ${ }^{18}$. Por otro lado, enuncia las contradicciones entre lo que se entiende por las diversas izquierdas y sus metodologías.

Aún así, dentro del movimiento, la acción colectiva disruptiva sirvió a su vez para condensar sentidos e imaginarios que sintetizaban el papel histórico de la lucha de la clase obrera. Esa construcción de un mito, de un imaginario

17 Entrevista a Andrés, idem anterior.

18 El caso de Andrés es uno de los más interesantes como expresión de un militante de base que duda y critica al movimiento del que forma parte, pero a la vez intenta mantenerse en el mismo. Su lógica reflexiva fue tan desbordante que escribió un pequeño libro autobiográfico donde relata detalles de su vida y de las lucha del movimiento de desocupado en el cual participó. 
ligado a las visiones de la izquierda y del peronismo, permitió reconstruir desde un plano utópico y real los sentidos de la movilización y de la acción en los barrios y sindicatos. Sin esa mística, alimentada de distintas formas, la mecánica de participación se caería, porque los sujetos se concebían a sí mismos como parte de un proyecto, que supone una historicidad donde se inscribe la demanda en el momento de interpelación al orden presente. Los movimientos disputan lugares, espacios y memorias, por eso su articulación con un proyecto histórico, donde se desarrolla una idea del futuro, puede alcanzar diferentes niveles.

Otro punto significativo se encuentra en la conciencia. La urgencia y la necesidad implicaron causas profundas que los propios actores asumieron como formas de negación en la construcción de una identidad de clase. Sobre este debate, creemos que las entrevistas realizadas resultan ambivalentes, ya que expresan las complicaciones organizativas, lingüísticas y las formas en que actúan las ideas dominantes para contener el conflicto social y la "identidad rebelde".

Es humillante para un trabajador que yo te diga lo que tenés que hacer para recibir comida, aun en el marco de las mejores intenciones (...) y esos errores el movimiento popular y la izquierda los ha cometido (...) tenemos que aprender de eso, tenemos que autocriticarnos (...) nuestra generación fue la generación de la resistencia, el mundo cambió (...) es otro y nosotros somos parte de ello... heroica como generación, pero no pudimos dirigirlo muy bien...a los dirigentes y me incluyo les cuesta mucho...esta idea de que me la se toda es una idea complicada porque los vicios son los vicios (...) los luchadores merecen el reconocimiento que merecen (...) necesitamos contar una historia que tuvo enormes contradicciones $(\ldots){ }^{19}$

El silencio más significativo fue el de las formas de machismo que existieron en las organizaciones de desocupados. La mujer tuvo un rol preponderante en el movimiento de desocupados/as; a pesar de ser el sujeto social con mayor índice de precariedad laboral e informalidad, fue la primera en manifestarse frente a la desocupación y el hambre, ocupando las primeras filas de combate. Si bien el reconocimiento del papel de las mujeres fue reconocido por las propias organizaciones, sus tareas estuvieron vinculadas al orden doméstico, lo que impuso a las mujeres un rol pasivo que les impidió ser parte de la dirección organizativa del movimiento.

El patriarcado se manifestó de diferentes formas: 1) En la nueva asignación del rol de la mujer como reemplazante del hombre proveedor, en ese momento 
derrotado por la desocupación. La mujer como luchadora del orden doméstico y laboral; 2) La participación escasa de la mujer en el ámbito directivo o cuando lo adquiere emulando actitudes patriarcales; 3 ) La división de tareas en el orden productivo, otorgando un papel al hombre (emprendimientos mecánicos, de carpintería, soldaduría, etc.) y otro a la mujer (cocinera, ama de casa, personal de limpieza, etc.).

En determinados momentos, las mujeres estuvieron a cargo de las tareas administrativas, pero siempre en última instancia fueron los varones, jefes o dirigentes, los que tomaron las decisiones principales o fueron sujetos de diálogo con el gobierno. Lo más interesante fue la forma en que se aceptaban tales configuraciones y tareas.

PB: ¿Ana, qué rol tuvieron las mujeres para ustedes en todo el proceso?

Ana: Las mujeres participaron poco, cuando ya salía del rol político, porque yo estaba más comprometida con el partido, ya ahí ya no actuaba yo. Solamente actuaba cuando venía con fuerza política. Así que poco rol. Apoyaban, estaban de acuerdo... Se encargaban de tareas puntuales digamos, ayudaban a cocinar... hacían el aguante $(\ldots) .^{20}$

Es posible que este tema se encuentre mediatizado por un presente donde el feminismo se erige como imperativo cuestionador de todas las prácticas, en todas las organizaciones. De esta manera podría inferirse que algunas reinterpretaciones desde el presente buscan afirmar lo positivo en las relaciones entre géneros, guardando en el olvido las relaciones desiguales.

\section{CLAVES PARA COMPRENDER LA FORMACIÓN DE UNA IDENTIDAD COLECTNA}

Para percibir entonces el movimiento resulta central preguntarse que se comprendía por trabajo y como se estructura una identidad a partir de su reclamo. El trabajo - como demanda simbólica y material - se convirtió en uno de los ejes transversales de la problemática de los desocupados. Históricamente, se lo relacionó con un momento particular en la conformación del Estado benefactor, expresando un derecho adquirido, una demanda popular y un resultado de la propia lucha colectiva.

Existe un factor económico y cultural en la apropiación del trabajo y en la creencia de que ha sido el único medio para obtener un status social en la

Entrevista a Ana, idem anterior. 
modernidad. Si ese imaginario de integración social y de expectativas de bienestar se hizo añicos ante una situación social signada por el deterioro de las condiciones y posibilidades de empleo (principalmente en la década de 1990), la demanda de trabajo - ante las clases dominantes - supuso, por un lado la continuidad de las experiencias, representaciones e imaginarios populares (el trabajo como derecho) y, por otro, la interpelación al orden social, manifestándose colectivamente contra la capacidad estructural del sistema para satisfacer esa demanda.

Por ello, la instrumentación de planes a través del Estado para paliar la grave crisis social, implicó la adquisición de nuevos derechos colectivos y la búsqueda de autonomía en términos de su obtención, ya que de antemano se preveía la disputa con el poder político, ante la dependencia generada.

A partir de la inferencia de los principales significantes que aparecen en los actores entrevistados, hemos podido comprender la importancia productiva en términos identitarios que tiene el trabajo como generador de una demanda legítima, investida de un sentido ético de recomposición ligada a la dignidad. Algunos autores, como MANEIRO, FARIAS Y SANTANA (2008), destacan la articulación de tres aspectos identitarios en los MTD (trípode general de articulación), que refiere a una vinculación orgánica entre una forma particular de protesta - los piquetes -, un sector específico de la clase trabajadora - los trabajadores desocupados -, y una demanda hegemónica - empleo y planes asistenciales - que constituyen el sustento de la acción territorial de los propios movimientos.

El valor social asignado al trabajo asalariado, expresado en las entrevistas realizadas, nos permitió comprender su relevancia histórica como eje articulador, más allá de su carencia fáctica. Esta representación constituyó parte de la subjetividad social de los sectores populares y se presentó como uno de los fundamentos legitimadores de su reclamo, retomando una positividad en la identidad del trabajador (MANEIRO, 2012). Esta percepción identificatoria implicó a su vez una articulación entre las experiencias de lucha de una izquierda contestataria, que tenía su peso en algunos sindicatos combativos y en diversas organizaciones populares. El trabajo se conformó como un elemento que generó integración y constituyó un aliciente para la movilización. Claramente, la orientación a la lucha define una identidad fundante en el desocupado organizado. El trabajo contiene la posibilidad de acceder a bienes básicos, una posición social digna, protección y estabilidad. Por ello, las acciones de los desocupados se orientan en muchos casos a restituir sentidos 
históricos ligados a una ética y cultura del trabajo (RETAMOZZO, 2006). Los sentimientos de culpa (subjetividad culpógena como hablaba Hector "Toty" Flores referente de un MTD del conurbano) actuaron como mecanismos de disciplinamiento en el proceso de asimilación del desocupado como responsable de su situación. La acción colectiva permite, dentro del movimiento, restituir un proceso, legitimando al mismo acto la necesidad material, la necesidad simbólica o de reconocimiento y la necesidad ideológica o de compromiso.

Por ello, las visiones instrumentalistas que solo observan a las organizaciones como espacios que usan los individuos para extraer recursos y beneficios, no comprenden la lógica intrínseca que conjuga el proceso de identificación y conciencia: no se moviliza por el "pancho, el chorizo y la cocacola", como suele repetirse despectivamente, sino por un sentido de clase, de negación de derechos sociales y por el descubrimiento de la capacidad de generar una politización de su propia situación.

La identidad es un proceso dinámico de configuración subjetiva estable (DE LA GARZA, 2001) ${ }^{21}$, donde las mismas acciones colectivas impactan en la conformación de una subjetividad colectiva e incorporan nuevos sentidos o los reorganizan.

Entendemos que los sujetos reproducen y crean significados vinculados a configuraciones culturales y materiales, para darle sentido a sus propias cosmovisiones del mundo. Hay un conflicto permanente, donde se produce un proceso de operaciones subjetivas atravesadas por la hegemonía, que opaca o subalterna otros significados posibles. En este conflicto, juega un rol preponderante la apropiación que hacen las clases sociales de los sentidos culturales, a partir de su propia historia como grupo, y los momentos históricos que contextualizan cierta apropiación y reelaboración.

Las personas que participaron en las organizaciones de desocupados inscribieron su experiencia en un entramado de interdependencias (donde se incluyen relaciones de parentesco, vecindad, trabajo, pertenencias políticas, etc.) que relacionamos con una perspectiva experiencial, para referir a una mirada que, tomando distancia de los modelos formales, busca restituir la

21 La configuración subjetiva propuesta por ENRIQUE DE LA GARZA TOLEDO (2001) siguiendo al propio ZEMELMAN, permite comprenderla como un proceso móvil que articula elementos (códigos), heterogéneos (cognitivos, emotivos, éticos, estéticos, etc) para revestir de significados a situaciones particulares, donde puede haber elementos contradictorios. Los códigos no están exentos de disputas, poder y antagonismos. El concepto es heurístico y puede ayudar a reconstruir dimensiones complejas. 
dimensión vivida de la participación y el involucramiento político.

Ser ocupado y desocupado significaba un tránsito entre dos estados muy dinámicos que van formando una identificación que sobrepasa el sentido de la falta de empleo. Ser trabajador y tener dignidad eran sentidos como elementos de cohesión muy fuertes, que implicaban relaciones con un pasado-presente que se transformaba rápidamente, y que posibilitaba nuevas identificaciones subjetivas y de conciencia política.

Por otro lado, ser además militante de una organización de desocupados, implicaba una identificación que relacionaba su condición estructural con su conciencia política. No solo era una de las tantas condiciones en la que se definía una experiencia de vida, sino que también marcaba una diferenciación con los desocupados que no se movilizaban, o que "pretendían obtener beneficios" sin participar políticamente. Esa era una imagen positiva y hasta heroica del militante social, que se alimentaba en las propias acciones colectivas, creando un ethos identitario que generaba una pertenencia y un sentido.

Durante la formación de los MTD, el discurso mediático tenderá a equiparar el sentido positivo del término piquetero con una definición despectiva, violenta y anti social, con el fin de estigmatizarlo y criminalizar la protesta (ARTESE, 2011). En este sentido, en la arena de la lucha ideológica discursiva, se generaron relatos por parte de los medios de comunicación que definieron la verdad o falsedad de los hechos, su carácter moral (justo o injusto) y político- jurídico en cuanto a la legalidad, legitimidad o peligrosidad institucional de las acciones, con el objetivo de deslegitimar y estigmatizar la protesta.

Aparece la idea del compromiso político y la militancia como una elección de vida que se llevará por siempre. Pero también podemos observar contradicciones, como la de "hacerse responsable de tareas que no desea", "participar en lugares que no se quiere", "hablar en acto públicos", "ir a manifestaciones para hacer número", entre otras expresiones que sintetizan la idea de estar en la organización por compromiso (político, colectivo) o estar por necesidad (interés económico, individual). Estas tensiones convivieron en la mayoría de los militantes de base y en los referentes jóvenes, como vivencias que pusieron en discusión su participación y continuidad al interior de las organizaciones. Estas situaciones nos llevan a pensar en las tensiones entre los marcos propuestos por las direcciones hegemónicas y el grado de consenso que generaban en las bases. 
El movimiento de trabajadores desocupados tenía como característica la heterogeneidad en su conformación. Esta característica puede observarse en la aglomeración de vivencias, experiencias y trayectorias de los participantes, en sus afinidades políticas, pero también en el atravesamiento generacional, de género y de pertenencia de clase.

Casi tres cuartas partes de los adherentes al movimiento fueron mujeres, donde reposó gran parte de la organización administrativa del movimiento, sin contar las innumerables veces que fueron cuerpo de los hechos de rebelión, poniéndose al frente de las luchas. Sin lugar a dudas, el movimiento lejos estuvo de impulsar el feminismo en sus prácticas sociales, aunque intentó generar un clivaje de relaciones menos desiguales. En general, mantuvo una división de tareas, tendiendo los varones a ocupar cargos directivos y de control ${ }^{22}$.

La composición generacional ${ }^{23}$ de las organizaciones de desocupados revela la articulación entre dos perfiles generacionales diferentes: por un lado, el componente de obreros desocupados ligados al trabajo estable, con un alto grado de conciencia profesional, calificados, con experiencia laboral y un pasado ligado a la sociedad salarial (personas entre 30 y 55 años, aproximadamente); y por otro, un sector de desocupados jóvenes con una conciencia más proletaria, baja calificación, escasa trayectoria laboral, inmersos en situaciones de pobreza, vivenciadores de los programas asistenciales (en la franja de los 16-29 años). Esta frontera era muy delgada, y se percibe en términos de expectativas, motivaciones y en las realidades generacionales.

La visión de una juventud corrompida y con dificultades de asimilar la lucha fue una constante en las estrategias de acción propias del movimiento que invocó a numerosas prácticas normativas para encauzar a esa juventud en sus sentidos y demandas. La diferencias generacionales expresaron un componente de primer orden a la hora de tomar decisiones importantes que fueron claves en los momentos de intensidad de la luchas de clases.

El sentido de pertenencia de clase tuvo una incidencia fundamental, al inscribirse los desocupados en trayectorias laborales atravesadas por la inestabilidad y la precariedad, la sensación de una erosión en los marcos

22 Esto no significa que las organizaciones no advirtieran sobre el potencial organizativo de las mujeres y como vehículo de necesidades compartidas. Es más, las mujeres ganaron en muchos aspectos un protagonismo inusual que en los sindicatos estuvo lejos de aparecer afirmando un principio de identificación autónoma.

23 En este sentido comprendemos la noción de generación no simplemente desde un punto de vista cronológico sino a los procesos históricos en que se sociabiliza una persona o un colectivo de sujetos. 
sociales y de prestigio, de consumo y de derechos básicos. Las clases medias se vieron involucradas en procesos de movilización social que rompieron los moldes que la separaban de los sectores populares. La pobreza y la desocupación se convirtieron en temas comunes de permanente tensión, que aunaron identidades entre fracciones sociales dispersas.

La retorica discursiva del movimiento se transformó en un sentido identificatorio, que se sintetizó en el propio núcleo de militantes como motivacional y consecuente. Muchas veces, esa retórica lanzaba una serie de exigencias que proponían un cambio social rotundo al sistema (a veces de forma utópica) y avanzaba en la línea de organizar políticamente a los desocupados.

La identidad de los desocupados dentro de una organización también estuvo mediada por mecanismos de control y evaluación por parte de los propios partidos o referentes que la impulsaban. Esa "coerción social" se expresaba en las decisiones que "bajaban políticamente" para la realización de acciones colectivas, o en las formas de pensar la situación económica con una mirada que pocas veces privilegiaba los sentidos locales/barriales. Las reglas abundaban con el objetivo de encaminar a los "buenos militantes" hacia prácticas eficaces en otros ámbitos. Para muchos de los protagonistas - aunque con diferencias - se entendía que había que participar en las marchas y movilizaciones para enfrentar al sistema, pero también para "ser un bulto de masas" que expresaba el énfasis en "lo numérico", en la cantidad por sobre la conciencia política. La necesidad de la gestación de una moral revolucionaria, apostando a la creación de un hombre nuevo y una mujer nueva, se debía expresar en la constancia cotidiana sin impaciencia y sin conformismos, siendo coherentes entre el decir y el hacer, entre la línea y la conducta.

Si la cantidad define la fuerza política y su capacidad de negociación con las patronales, es evidente que el número no puede relacionarse inmediatamente con la conciencia política de masas, o con la fuerza del vínculo entre las motivaciones reales de los actores con el de las organizaciones. A pesar de estas dificultades, la masificación del fenómeno permite establecer que en la acción de movilizar se juegan factores de poder, que se van imbricando internamente en los militantes, y les permite verificar y ser parte de esa realidad.

\section{CONCLUSIONES}


A través de un breve análisis de los principales significantes de los actores sociales se realizó una aproximación exploratoria a fin de evaluar los mecanismos de formación de la conciencia de clase y de los problemas metodológicos a la hora de realizar entrevistas sobre militantes políticos/barriales/sindicales ligados a los movimientos de trabajadores desocupados.

La historia oral está íntimamente relacionada con la constitución de memorias colectivas. La memoria es parte de un conjunto seleccionado de recuerdos que no se construyen al azar sino que se organizan de acuerdo a criterios personales, emocionales, racionales, sociales y/o culturales, significativos para la organización. Las memorias se construyen, elaboran, organizan en la voluntad de incursionar en el sentido de las vivencias del pasado (JELIN, 2002). La configuración de una memoria narrada implica el trabajo de organización de las experiencias que los individuos hacen de sí mismos y de su propia exposición, permeada por el/la investigador/a.

Jorge Aceves Lozano habla de la memoria como un rompecabezas, como un constructo problemático, como un laberinto donde aparecen trayectorias dispersa (ACEVES LOZANO, 2008). En este sentido, la percepción de las entrevistas nos invita a pensar en las invenciones consensuadas de un pasado relevante y significativo, donde los mitos y silencios se combinan permanentemente.

Las posiciones estructurales de los actores sociales repercuten en las formas en que son invitados a recordar colectivamente. Sin embargo, la experiencia moldea formas diversas en torno al grado de significatividad que el sujeto tuvo con su pasado. La entrevistas a militantes políticos conlleva un conjunto de problemas metodológicos que solo pueden resolverse en la práctica misma. Al diseño de una entrevista que tuviera un acercamiento etnográfico, en tanto forma de dialogo y construcción con un otro, hemos dispuesto la conjunción con diversos ejes como la cuestión de género, edad y la pertenencia de clase, como claves para comprender los sujetos sociales.

Los diversos significantes que aparecen en las entrevistas a los actores del movimiento como necesidad, conciencia, militancia y lucha, forman parte de un conjunto de interpretaciones sobre el hacer y el ser dentro de una organización, explican las causas profundas que en parte movilizan a los sujetos colectivos, y conforman la existencia de un ethos de militancia ligado a reivindicaciones como el trabajo y la dignidad.

Dotar a un movimiento de una tradición histórica implica recuperar su 
memoria desde la voz de los sujetos participantes. En este sentido, retomamos lo expresado por Gerardo Necoechea Gracia cuando dice que "la memoria es un campo de acción en que continuamente se negocian las percepciones del ser $y$ estar en el mundo" (NECOECHEA GRACIA, 2006). Tratamos de comprender una experiencia en su doble sentido - formada por un estar en el mundo y por un accionar que repercute en su manera de ver el mundo -, donde la acción cobra sentido, en tanto es simultáneamente repetición e innovación. De la realización de las entrevistas y de la observación cuantitativa de los hechos de conflictividad, se ha podido comprobar un activo proceso de creación de significados que nos permiten ahondar sobre las concepciones propias de las experiencias de militancia política.

\section{REFERÊNCIAS}

ACEVES LOZANO, J. Memorias convocadas. Los concursos de testimonios como fuente para la historia oral contemporánea. Espiral, Estudios sobre Estado y sociedad, v. XIV, n. 41, Universidad de Guadalajara, México, pp: 9-40, 2008.

ARTESE, M. Las acciones colectivas de protesta y el conflicto social en la Argentina de 1990: Apuntes sobre sus caracterizaciones. Sociohistórica, n. 28, Universidad Nacional de La Plata, La Plata, pp: 107- 129, 2011.

AZPIAZU, D. Y BASUALDO, E. Las privatizaciones en la Argentina. Génesis, desarrollo y principales impactos estructurales. Buenos Aires: FLACSO, Facultad Latinoamericana de Ciencias Sociales, 2004.

\section{BECHER, P. El Movimiento de Trabajadores Desocupados en Bahía Blanca}

(1995- 2003): organización y conflictividad. Tesis de maestría en Sociología por la Universidad Nacional del Sur, Bahía Blanca, no publicada.

BENADIBA, L.; PLOTINSKY D. De entrevistadores y relatos de vida. Buenos Aires: Imago Mundi, 2005.

D'amico M. y Pinedo, J. Debates y derivas en investigaciones sobre los piqueteros. Una bitácora de lectura. Sociohistórica, n. 25, Universidad Nacional de La Plata, La Plata, 2009.

DE LA GARZA TOLEDO, E. Subjetividad, cultura y estructura. Revista Iztapalapa, n. 50, México, pp: 83-104, 2001. 
DUBET, F. La experiencia sociológica [1994], Barcelona: Ed. Gedisa, 2011.

FANÓN, F. Los condenados de la tierra [1961], Buenos Aires: FCE, 2007.

FERNANDEZ HELLMUND, P. Solidaridad argentina con la revolución Sandinista. Reflexiones sobre el trabajo de campo. En HERNÁNDEZ, G. (Comp.). Lo dicho y los hechos, Bahia Blanca: Ed. El Colectivo, pp: 47- 76, 2013.

GUBER, R. La etnografía. Método, campo y reflexividad. Buenos. Aires: Norma, 2001.

JELIN, E. Los trabajos de la memoria. Madrid: Siglo XXI, 2002.

MANEIRO, M. De encuentros y desencuentros: Estado, gobierno y Movimiento de Trabajadores Desocupados. Buenos Aires: Ed. Biblos, 2012.

MANEIRO, M.; FARÍAS, A.; SANTANA, G. Divergencias y homogeneidades en el movimiento de trabajadores desocupados. Ponencia presentada en las II Jornadas de Intercambio de Proyectos de Investigación y Extensión. Buenos Aires: Facultad de Ciencias Sociales-UBA, 2008.

MANZANO, V. Tradiciones asociativas, políticas estatales y modalidades de acción colectiva: análisis de una organización piquetero. Revista Intersecciones en Antropología, n. 5, Buenos Aires: Facultad de Ciencias Sociales, UNCPBA, 2004.

MELUCCI, A. Asumir un compromiso: identidad y movilización en los movimientos sociales. Zona Abierta, N. 69, Madrid, pp: 153-180, 1994.

NECOECHEA GARCÍA, G. Después de vivir un siglo. Ensayos de historia oral. México: Instituto Nacional de Antropología e Historia, pp: 11-18, 2006.

OVIEDO, L. Una historia del movimiento piquetero. De las primeras Coordinadoras al Argentinazo. Buenos Aires: Rumbos ,2004.

PINEDO, J. Hacer lo que los otros, por el momento, no pueden hacer. Proyecto militante, prácticas de anclaje territorial, relaciones de interdependencia y noción de compromiso en un Movimiento de Trabajadores Desocupados. Tesis de maestría en ciencia sociales, Universidad Nacional de La Plata, 2009.

PORTELLI, A. Lo que hace diferente a la historia oral. En SCHWARZSTEIN, D. 
(comp.). La historia oral. Buenos Aires: CEAL, 1991.

POZZI, P. Esencia y práctica de la historia oral. Revista Tempo e Argumento, v. 4, n. 1, enero-junio, Universidade do Estado de Santa Catarina, Florianópolis, pp: 61- 70, 2012.

QUIRÓS, J. Cruzando la Sarmiento. Una etnografía sobre piqueteros en la trama social del sur del Gran Buenos Aires. Buenos Aires: Antropofagia, 2006.

Retamozo, M. El movimiento de trabajadores desocupados en Argentina. Subjetividad y acción en la disputa por el orden social. Tesis de Doctorado. México, FLACSO, 2006.

SCHWARZSTEIN, D. Fuentes orales en los archivos: desafíos y problemas. Historia, Antropología y fuentes orales, n. 27. Buenos Aires: Ed. Apariencias y compromisos, pp: 167- 177, 2002.

Svampa M. y Pereyra, S. Entre la ruta y el barrio: la experiencia de las organizaciones piqueteras. Buenos Aires, Biblos, 2003.

SVAMPA M. Cambio de época: movimientos sociales y poder político. Buenos Aires: Clacso libros: OSAL: El Colectivo, 2008.

VASILASCHIS DE GIALDINO, I. Estrategias de investigación cualitativa. Buenos Aires: Gedisa, 2007.

VASQUEZ, M. Experiencia social y militancia política. Los referentes jóvenes de un Movimiento de Trabajadores Desocupados. En MASSETTI, A., VILLANUEVA, E.; GÓMEZ, M. (Comp.). Movilizaciones, protestas e identidades políticas en la Argentina del Bicentenario. Buenos Aires: Trilce, pp: 197- 224, 2010. 
Movimento de Trabalhadores Desempregados de Bahia Blanca (Argentina), no período 1995-2003: uma abordagem a partir de seus significantes sócio-políticos

\begin{abstract}
Resumo: A partir do uso da história oral e metodologia qualitativa, este artigo irá investigar as relações sociais estabelecidas trabalhadores desempregados e suas organizações na cidade de Bahia Blanca (Argentina), no período 1995-2003, analisando os vários significados produzidos na ação coletiva, a organização social, a militância e estratégias de política/ofensivas táticas defensivas como corpos sociais em disputa. Neste contexto, o papel dos desempregados dentro da classe trabalhadora e análise de contenda nos permitem reconstruir os movimentos de protesto na década de 1990, no âmbito da acumulação capitalista durante o período da conversibilidade, tentando revelar a sua complexidade, a sua experiências de luta e continuidades e rupturas com o passado-presente.
\end{abstract}

Palavras-Chave: História oral. Movimento de Trabalhadores Desempregados. Militância. Organização política.

The Movement of Unemployed Workers of Bahia Blanca (Argentina) in the period 1995-2003: an account from their socio-political significants

\begin{abstract}
Based on the use of oral history and qualitative methodology, this article will investigate the social relations established by unemployed workers and their organizations in the city of Bahia Blanca (Argentina) in the period 1995-2003, analyzing the various Signifiers produced in collective action, social organization, political militancy, and defensive strategies / tactics-as social bodies in dispute. In this sense, the role of the unemployed within the working class and the analysis of their conflict make it possible to reconstruct the protest movements in the 1990s, within the framework of capitalist accumulation during the convertibility stage, trying to reveal their complexity, their Experiences of struggle and the continuities or ruptures with the past-present.
\end{abstract}

Keywords: Oral History. Movement Of Unemployed Workers. Militancy. Political Organization. 


\section{ANEXO}

Cuadro de información básica de los/as entrevistados/as y características principales. Sus nombres fueron cambiados a fin de preservar la identidad de los sujetos.

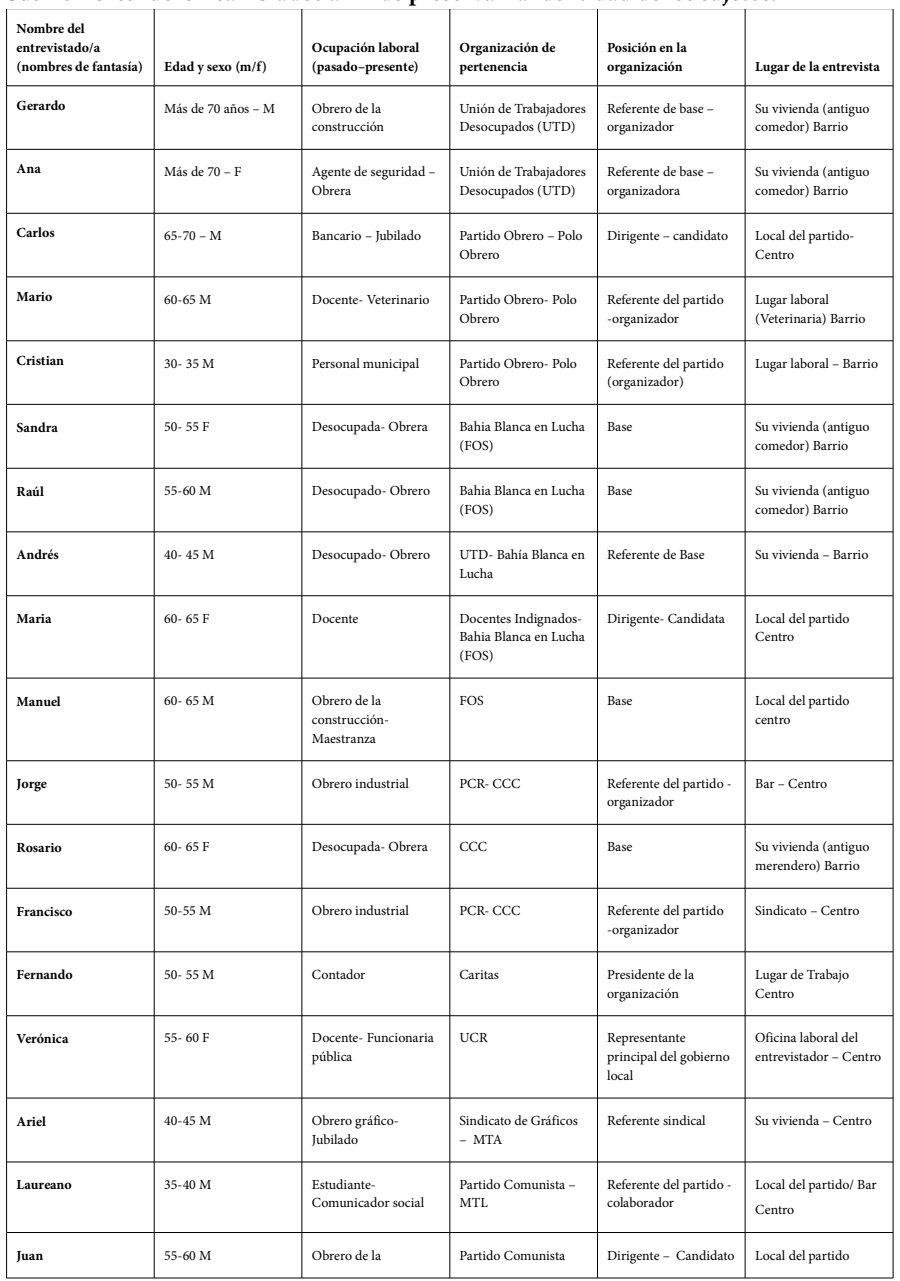




\begin{tabular}{|l|l|l|l|l|l|}
\hline & & construcción & MTL & Centro \\
\hline Manolo & $65-70 \mathrm{M}$ & $\begin{array}{l}\text { Estudiante- Agente } \\
\text { municipal }\end{array}$ & $\begin{array}{l}\text { Partido Comunista - } \\
\text { MTL }\end{array}$ & $\begin{array}{l}\text { Referente del partido - } \\
\text { organizador }\end{array}$ & $\begin{array}{l}\text { Local del Partido } \\
\text { Centro }\end{array}$ \\
\hline Emiliano & $60-65 \mathrm{M}$ & Bancario & CTA & Dirigente - Candidato & Su vivienda - Barrio \\
\hline Alejandro & $30-35 \mathrm{M}$ & $\begin{array}{l}\text { Estudiante- Obrero } \\
\text { industrial }\end{array}$ & $\begin{array}{l}\text { Partido Comunista- } \\
\text { MTL }\end{array}$ & $\begin{array}{l}\text { Referente del partido - } \\
\text { colaborador }\end{array}$ & $\begin{array}{l}\text { Local del partido } \\
\text { Centro }\end{array}$ \\
\hline Ramiro & $65-70 \mathrm{M}$ & Desocupado- Bancario & Polo Obrero & $\begin{array}{l}\text { Referente del partido - } \\
\text { organizador }\end{array}$ & Su vivienda - Barrio \\
\hline Cecilia & $60-65 \mathrm{~F}$ & Enfermera- Jubilada & Partido Obrero & $\begin{array}{l}\text { Referente sindical - } \\
\text { colaboradora }\end{array}$ & Su vivienda - Barrio \\
\hline Mauro & $50-55 \mathrm{M}$ & Docente & $\begin{array}{l}\text { Docentes Indignados- } \\
\text { Bahia Blanca en Lucha }\end{array}$ & $\begin{array}{l}\text { Referente sindical - } \\
\text { colaborador }\end{array}$ & Su vivienda - Barrio \\
\hline Bruno & $50-55 \mathrm{M}$ & Abogado & ADICBBA - UOCRA & $\begin{array}{l}\text { Referente sindical - } \\
\text { organizador }\end{array}$ & $\begin{array}{l}\text { Lugar de trabajo } \\
\text { Centro }\end{array}$ \\
\hline Ernesto & $60-65 \mathrm{M}$ & Docente & Docentes Indignados & $\begin{array}{l}\text { Referente sindical } \\
\text { Correo } \\
\text { Electrónico }\end{array}$ \\
\hline
\end{tabular}


El Movimiento de Trabajadores Desocupados de Bahia Blanca en el período 1995-2003 